\title{
Correction to: COVID-19 nationwide lockdown and physical activity profiles among North-western Italian population using the International Physical Activity Questionnaire (IPAQ)
}

\author{
Federico Abate Daga ${ }^{1,2}$ (D) Samuel Agostino ${ }^{2} \cdot$ Serenella Peretti $^{2} \cdot$ Luca Beratto $^{1,2}$
}

Published online: 29 November 2021

(c) Springer-Verlag Italia S.r.l., part of Springer Nature 2021

\section{Correction to: Sport Sciences for Health (2021) 17:459-464 https://doi.org/10.1007/s11332-021-00745-8}

The Ref. [13] has been incorrectly published in the original publication. The complete correct reference is given below.

Chen P, Mao L, Nassis GP, Harmer P, Ainsworth BE, Li F (2020) Coronavirus disease (COVID-19): the need to maintain regular physical activity while taking precautions. J Sport Health Sci 9(2):103-104. https://doi.org/10.1016/j. jshs.2020.02.001

Publisher's Note Springer Nature remains neutral with regard to jurisdictional claims in published maps and institutional affiliations.

The original article can be found online at https://doi.org/10.1007/ s11332-021-00745-8.

Federico Abate Daga

federico.abatedaga@unito.it

Samuel Agostino

samuel.agostino@unito.it

Serenella Peretti

serenella.peretti@unito.it

Luca Beratto

luca.beratto@unito.it

1 Department of Medical Sciences, University of Turin, Turin, Italy

2 Adapted Training and Performance Research Group, School of Exercise and Sport Sciences, University of Turin, Turin, Italy 